\title{
Erratum to: Dose-Response Relationships of Balance Training in Healthy Young Adults: A Systematic Review and Meta-Analysis
}

\author{
Melanie Lesinski $^{1}$ Tibor Hortobágyi ${ }^{2}$. Thomas Muehlbauer ${ }^{1} \cdot$ Albert Gollhofer $^{3}$ • \\ Urs Granacher ${ }^{1}$
}

Published online: 8 February 2016

(C) Springer International Publishing Switzerland 2016

\section{Erratum to: Sports Med (2015) 45(4):557-576 \\ DOI 10.1007/s40279-014-0284-5}

Page 559, column 2, section 2.4, paragraph 2, lines 47-52: The following sentence, which previously read:

Within-subject $\mathrm{ES}_{\mathrm{dw}}\left(\mathrm{ES}_{\mathrm{dw}}= \pm\right.$ [mean pre-value - mean post-value]/SD pre-value) and between-subject $\mathrm{ES}_{\mathrm{db}}$ $\left(\mathrm{ES}_{\mathrm{db}}= \pm\right.$ [mean post-value intervention group - mean post-value control group]/pooled variance) were computed according to Cohen [15] (where SD is standard deviation).

Should read:

Within-subject $\mathrm{ES}_{\mathrm{dw}}\left(\mathrm{ES}_{\mathrm{dw}}=\right.$ [mean pre-value - mean post-value]/SD pre-value) and between-subject $\mathrm{ES}_{\mathrm{db}}$ $\left(\mathrm{ES}_{\mathrm{db}}=\right.$ [mean post-value intervention group - mean post-value control group]/pooled SD) were computed according to Cohen [15] (where SD is standard deviation).

The online version of the original article can be found under doi:10.1007/s40279-014-0284-5.

Urs Granacher

urs.granacher@uni-potsdam.de

1 Division of Training and Movement Sciences, University of Potsdam, Research Focus Cognition Sciences, Am Neuen

Palais 10, House 12, 14469 Postdam, Germany

2 Centre for Human Movement Sciences, University Medical Centre Groningen, Groningen, The Netherlands

3 Institute of Sport and Sport Science, Albert-LudwigsUniversity of Freiburg, Freiburg, Germany 